\title{
ACTINOMICOSE CUTÂNEA PRIMÁRIA dO PÉ SIMULANDO NEOPLASIA DE PARTES MOLES: RELATO DE CASO*
}

\author{
Renata La Rocca Vieira ${ }^{1}$, Gustavo de Souza Portes Meirelles², Elizabete Turrini², \\ Jane Yamashita ${ }^{3}$, Héverton César de Oliveira ${ }^{4}$, Artur da Rocha Corrêa Fernandes ${ }^{4}$
}

\begin{abstract}
Resumo Relatamos um caso de actinomicose cutânea primária do pé simulando neoplasia de partes moles, com revisão da literatura sobre sua incidência, aspectos clínicos, patológicos e de imagem. Utilizamos radiografias simples, ressonância magnética e estudo anatomopatológico. A importância do estudo se deve à raridade da enfermidade, localização atípica e, particularmente, ao diagnóstico diferencial com neoplasia de partes moles. Unitermos: Actinomicose; Pele; Pé.
\end{abstract}

Abstract Primary cutaneous actinomycosis of the foot mimicking a soft tissue neoplasm: a case report.

We report a case of a patient with primary cutaneous actinomycosis of the foot mimicking a soft tissue neoplasm. A literature review on the incidence, clinical features, pathology and imaging findings is also presented. The plain films and magnetic resonance imaging findings and the pathology results are presented. This paper reports a rare disease occurring in an atypical location, simulating a soft tissue neoplasm. Key words: Actinomycosis; Skin; Foot.

\section{INTRODUÇÃO}

A actinomicose é uma doença infecciosa granulomatosa crônica, rara, progressiva, causada, na maioria dos casos, pela bactéria Gram-positiva e anaeróbia Actinomyces israelii.

A lesão caracteriza-se por pus, fibrose e fístulas que drenam grânulos característicos. Tal infecção é particularmente frequiente na face, abdome, tórax e pelve $\mathrm{e}^{(1-4)}$. $\mathrm{O}$ esqueleto pode ser comprometido por disseminação local da infecção ${ }^{(5)}$.

Apresentamos um caso de actinomicose cutânea primária com achados de imagem simulando neoplasia de partes moles e de localização incomum.

\section{RELATO DO CASO}

Paciente do sexo masculino, branco, 31 anos de idade, natural de Pernambuco e

\footnotetext{
* Trabalho realizado nos Departamentos de Dermatologia e de Diagnóstico por Imagem da Universidade Federal de São PauIo/Escola Paulista de Medicina (Unifesp/EPM), São Paulo, SP.

1. Médica Residente do Departamento de Diagnóstico por Imagem da Unifesp/EPM.

2. Pós-graduandos do Departamento de Diagnóstico por Imagem da Unifesp/EPM.

3. Docente da Disciplina de Dermatologia da Unifesp/EPM.

4. Docentes do Departamento de Diagnóstico por Imagem da Unifesp/EPM.

Endereço para correspondência: Dra. Renata La Rocca Vieira. Rua Doutor Diogo de Faria, 650, apto. 33, Vila Clementino. São Paulo, SP, 04037-002. E-mail: renatalarocca@bol.com.br

Recebido para publicação em 18/9/2002. Aceito, após revisão, em 9/1/2003.
}

residente em São Paulo, SP, há dez anos, procurou o Serviço de Dermatologia da Escola Paulista de Medicina com história de tumoração no dorso do pé direito há um ano, após ter sofrido trauma local, com piora progressiva desde então. A lesão caracterizava-se por tumoração lenhosa de limites bem definidos, com discreto eritema e fístulas recobertas por crostas hemáticas,

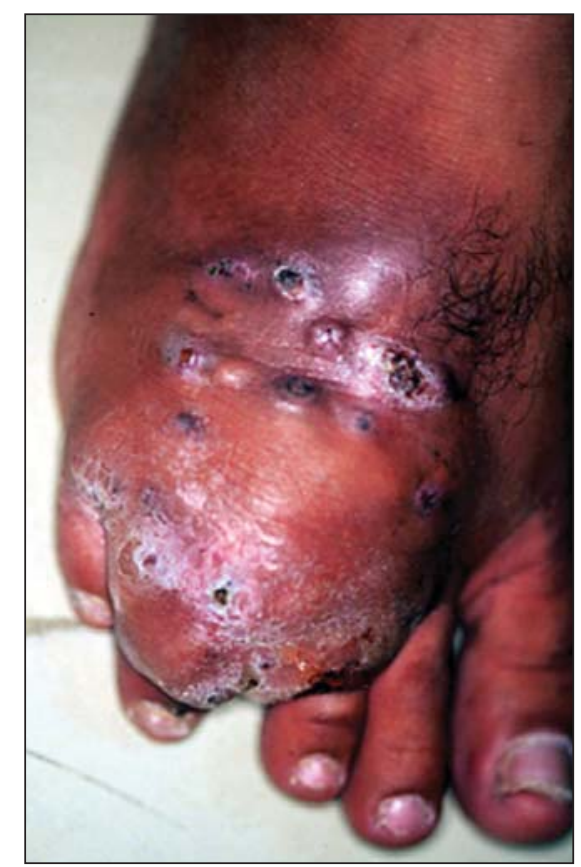

Figura 1. Tumoração no dorso do pé direito, com eritema, crostas hemáticas e fístulas drenando grânulos seropurulentos. com drenagem de grânulos seropurulentos (Figura 1).

A radiografia do pé evidenciou aumento de partes moles sem lesão óssea aparente (Figura 2), notando-se alargamento do espaço interdigital e intermetatarsiano entre o segundo e o terceiro raios.

A seguir, optou-se pela realização de ressonância magnética (RM) (Figura 3), que evidenciou extensa formação heterogênea com áreas cístico-necróticas, medindo cerca de $10 \times 5 \mathrm{~cm}$, acometendo os planos cutâneo, subcutâneo e muscular. Esta

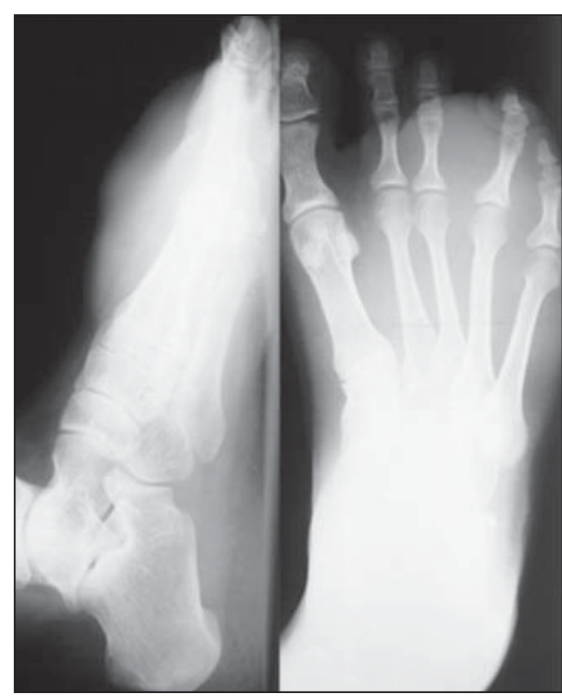

Figura 2. Radiografia do pé direito. Aumento do volume e da densidade das partes moles na região dorsal, sem evidências de lesão óssea. 

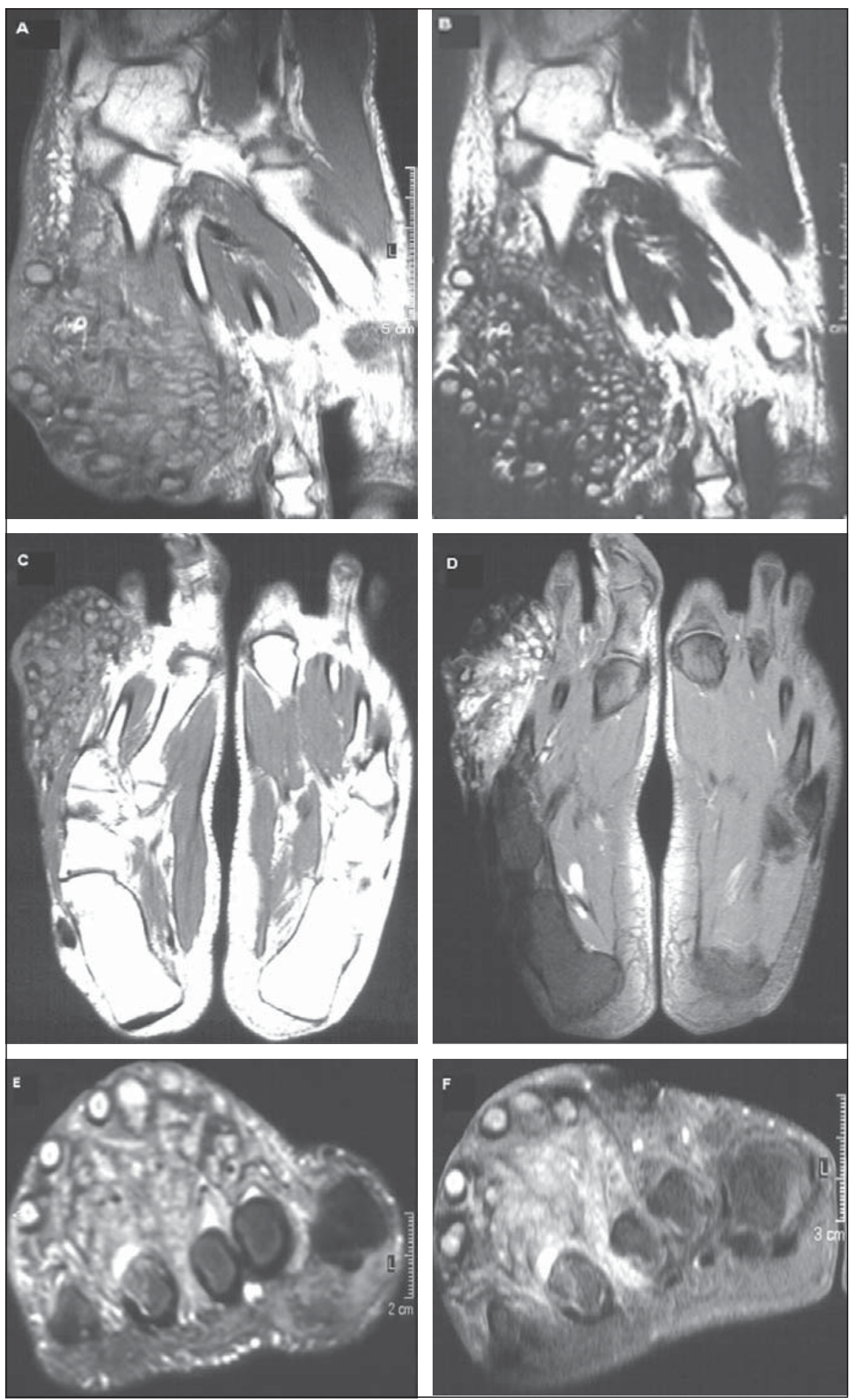

Figura 3. Ressonância magnética do pé direito em cortes axiais e coronais em seqüências ponderadas em T1 (A,C), T2 (B) e STIR (D,E). Formação heterogênea com áreas necróticas acometendo os planos cutâneo, subcutâneo e muscular. Estruturas ósseas sem alterações expressivas. Após injeção de gadolínio observase impregnação intensa e heterogênea da lesão (F).

formação insinuava-se entre os metatarsos e falanges proximais, principalmente entre os terceiro e quarto dedos, onde alargava o espaço interdigital e abaulava a pele, que se apresentava irregular e com soluções de continuidade (fístulas). Apresentava sinal intermediário e áreas de baixo sinal em T1. Nas sequiências "fast spin-echo" e com saturação do sinal de gordura observavamse pequenas áreas focais de hipersinal de aspecto vesicular, com cerca de $5 \mathrm{~mm}$ cada, que apresentavam sinal intermediário nas sequiências ponderadas em T1. Após a injeção de agente paramagnético, notou-se impregnação intensa e heterogênea da imagem descrita. Estruturas ósseas sem alterações expressivas ao exame por RM.

O estudo anatomopatológico da lesão biopsiada indicou processo inflamatório crônico supurativo com tecido de granulação e grânulos basofílicos característicos de actinomicose (Figura 4).

O paciente está em tratamento com sulfametoxazol-trimetoprim.

\section{DISCUSSÃO}

A actinomicose é causada, em 78\% dos casos, pelo Actinomyces israelii, bactéria anaeróbia filamentosa, Gram-positiva, que compõe a flora normal da cavidade oral ${ }^{(1)}$. É uma infecção crônica progressiva supurativa, com fibrose e fístulas que drenam grânulos basofílicos ${ }^{(1,4-6)}$. Estes representam, macroscopicamente, as colônias bacterianas, que podem ser visibilizadas pelos métodos de Gram e de Grocott-Gomori ${ }^{(1,6)}$

Esta doença é mais freqüente no sexo masculino, com uma relação de $4: 1^{(1)}$. A infecção ocorre principalmente na face e no pescoço ${ }^{(\mathbf{1 , 5}, \mathbf{6})}$. Tal fato é justificado pela presença da bactéria na flora bucal e nasal. As infecções pulmonar e gastrointestinal também podem ocorrer.

$\mathrm{O}$ trauma é um importante mecanismo de infecção. Outros fatores predisponentes são aspiração de dentes e de corpos estranhos ${ }^{(6,7)}$. Pode haver disseminação hematogênica do microorganismo para fígado, baço, rins, sistema nervoso central, ossos e articulações. O comprometimento ósseo decorre geralmente de disseminação por contigüidade. A infecção dos ossos da mão pode ser secundária a mordida humana ${ }^{(6)}$.

Os diversos métodos de imagem, como a ultra-sonografia (US), a tomografia computadorizada (TC) e a RM são úteis na avaliação de infecções do sistema músculo-esquelético. A radiografia também pode fornecer informações ou indicar a próxima modalidade de exame por imagem para confirmar infecção óssea ou de partes moles. A US é útil na detecção e aspiração de coleções. A TC e, principalmente, a RM fornecem mais informações sobre a anato- 
Figura 4. Estudo anatomopatológico. A: Bactérias filamentosas Gram-positivas na periferia do grânulo parasitário (método de Gram). B: Bactérias com impregnação pela prata em forma de finos filamentos ramificados, dispostos na periferia do grânulo parasitário (método de Grocott-Gomori).
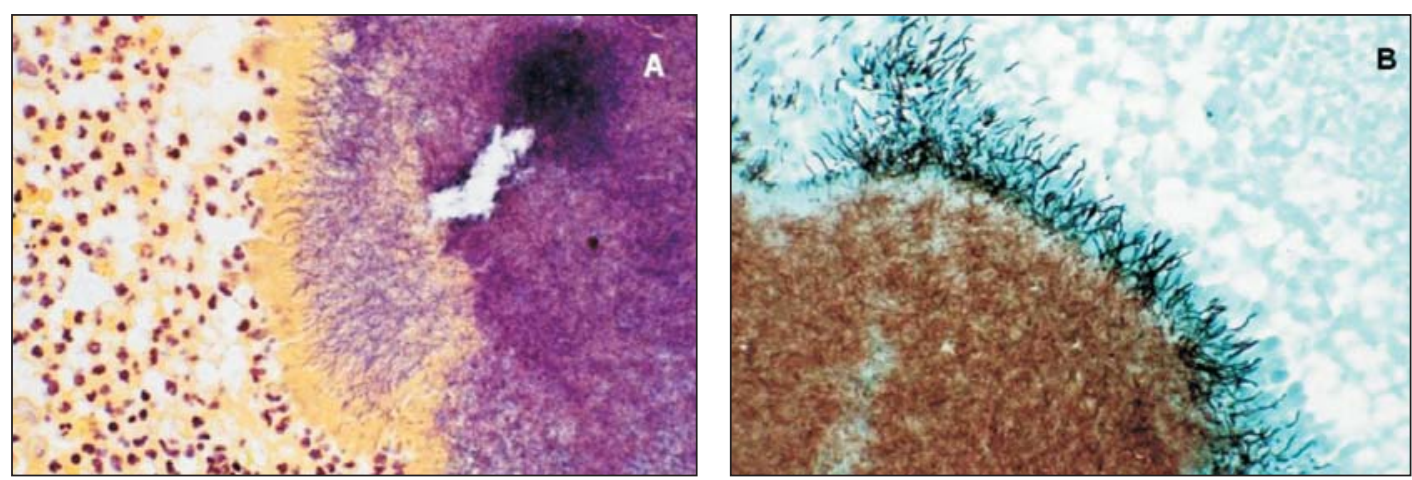

mia e extensão da infecção. O contraste na RM é ideal para a identificação do processo inflamatório e abscessos de partes moles, além de localizar a área infectada e detalhar melhor a relação da infecção com estruturas ósseas e neurovasculares ${ }^{(6)}$.

A cultura da bactéria é positiva em apenas $50 \%$ dos $\operatorname{casos}^{(\mathbf{1 , 4})}$. Nessas circunstâncias, o exame histopatológico é suficiente para fechar o diagnóstico, pois as colorações de Gram e de Grocott-Gomori permitem a identificação da bactéria com suas ramificações características ${ }^{(\mathbf{1})}$.

$\mathrm{O}$ tratamento consiste em antibioticoterapia prolongada com penicilina ou sulfametoxazol-trimetoprim ${ }^{(\mathbf{1 , 4})}$.

A avaliação por imagem desses pacientes segue o protocolo de abordagem das tumorações de partes moles, iniciando-se pela radiografia simples e pela US, incluindo a avaliação pelo Doppler para se afastar lesões de natureza vascular. A RM tem como vantagem a avaliação da extensão do comprometimento das partes moles e das estruturas ósseas, podendo ser utilizada para o estudo desses pacientes.
Com relação ao nosso caso, o aspecto macroscópico (tumoração com fístulas que drenam grânulos) e as características da lesão na RM foram semelhantes aos escassos relatos encontrados na literatura e, dessa forma, não puderam afastar a possibilidade de neoplasia de partes moles ${ }^{(\mathbf{5})}$. Com isso, foi necessário estudo anatomopatológico para confirmar o diagnóstico de actinomicose.

Massas de partes moles do pé são incomuns e, destas, $87 \%$ são benignas. As mais freqüentes são "ganglion" cístico e neurofibromatose. Esta ocorre principalmente na região plantar do médio pé, sendo importante causa de dor nesta região ${ }^{(8)}$.

Dentre as lesões malignas que ocorrem em partes moles do pé, a principal é o sarcoma sinovial e manifesta-se principalmente no retro pé ${ }^{(\mathbf{8})}$.

A importância do nosso estudo consiste em relatar um caso de infecção rara, com localização incomum, simulando neoplasia de partes moles nos métodos de imagem utilizados. Portanto, esta hipótese pode ser considerada dentre os diagnósticos dife- renciais nos pacientes com formação expansiva associada a lesão de pele envolvendo alguma extremidade.

\section{REFERÊNCIAS}

1. Barros N, Issa FKK, Barros ACSD, et al. Imaging of primary actinomycosis of the breast. AJR 2000; 174:1784-6.

2. Reiner SL, Harrelson JM, Miller SE, Hill GB, Gallis HA. Primary actinomycosis of an extremity: a case report and review. Rev Infect Dis1987;9:581-9.

3. Sardana K, Mendiratta V, Sharma RC. A suspected case of primary cutaneous actinomycosis on the buttock. J Dermatol 2001;28:276-8.

4. Verma KK, Lakhanpal S, Sirka CS, Khaitan BK, Raman M, Banerjee U. Primary cutaneous actinomycosis. Acta Derm Venereol 1999;79:327.

5. Kumar A, Detrisac DA, Krecke CF, Jimenez MC Actinomycosis of the thigh presenting as a soft-tissue neoplasm. J Infect 1991;23:187-90.

6. Resnick D, Niwayama G. Osteomyelitis septic arthritis and soft tissue infection organisms. In: Resnick D, ed. Diagnosis of bone and joint disorders. 3rd ed. Philadelphia, PA: WB Saunders, 1995: 2448-558.

7. Gayraud A, Grosieux-Dauger C, Durlach A, et al. Actinomycose cutanée péri-anale et fessière. Ann Dermatol Venereol 2000;127:393-6.

8. Berquist TH. Foot, ankle and calf. In: Berquist TH, ed. MRI of the musculoskeletal system. 4th ed. Philadelphia, PA: Lippincott Williams \& Wilkins, 2001:428-578. 